\title{
Phosphate Removal Ability of Calcined Paper Sludge from Aqueous Solution - Effect of Calcination Temperature
}

\author{
Kentaro Kimura and Takaaki Wajima
}

\begin{abstract}
In this study, removal behavior of phosphate from aqueous solution using calcined paper sludge was examined. Paper sludge is discharged as an industrial waste in paper making, and the amount increases annually with the use of the recyclable paper material. The paper sludge disposal becomes an important issue in paper industry, and new utilization is desired. In our previous study, we succeeded to prepare the porous material with high phosphate removal ability from aqueous solution by heating paper sludge at $800^{\circ} \mathrm{C}$. Phosphorus is one of the factors for eutrophication. Therefore, removal behavior of this calcined paper sludge for phosphate was examined to remove phosphate from aqueous solution. Paper sludge was dried and sieved under $250 \mu \mathrm{m}$, and calcined at 800 ${ }^{\circ} \mathrm{C}$ for 0 - 60 minutes in an electric oven. The sludge calcined for each calcining time were added to phosphate solution $(10 \mathrm{mM}$ $\mathrm{KH}_{2} \mathrm{PO}_{4}$ ), and stirred at $600 \mathrm{rpm}$ with magnet stirrer at room temperature. During stirring, phosphate concentration in solution was analyzed. Phosphate can be removed from aqueous solution using the sludge calcined for more than 20 minutes, due to the amorphous phase to form the phosphate mineral, brushite. From the results of phosphorus removal, reaction kinetics was analyzed using the pseudo-first-order kinetic model and pseudo-second-order model, and the experimental data fit much better to pseudo-first order model than to pseudo-second-order model.
\end{abstract}

Index Terms-Phosphate removal, calcined paper sludge, calcining time, reaction kinetics, recycling.

\section{INTRODUCTION}

The paper sludge is an industrial waste of the paper industry, which includes short fibers and the remained paint via manufacturing process of recycling paper. As waste paper recycling promotes, the discharges of paper sludge increase year by year. The current disposal method for paper sludge is mainly incineration and then landfill [1]. However, there is a shortage of landfill sites in Japan, and landfill is becoming difficult. Therefore, it is necessary to make new utilization for paper sludge, and there are some papers for paper sludge utilization, such as the zeolite, tobermorite [2], hydroxyapatite [3], carbonaceous adsorbents [4], and so on.

The eutrophication occurs at water areas all over the world such as sea, wetlands, and river, because phosphorus concentration in sewage and industrial effluent increases by human activities. On the other hands, it is predicted that the phosphorus ores as resources will be exhausted in several decades, and it is unevenly distributed [5]. It has a potential problem for the critical situation of a food production

Manuscript received October 19, 2016; revised November 28, 2016.

K. Kimura and T. Wajima are with the Department of Urban Environment Systems, Graduate School of Engineering, Chiba University, Japan (e-mail: afta3252@chiba-u.jp,wajima@tu.chiba-u.ac.jp). throughout the world [6].

From these situations, we tried to prepare a functional material with phosphorus removal performance from paper sludge. In a previous study, we reported that the paper sludge calcined at $800{ }^{\circ} \mathrm{C}$ has high phosphorus removal ability [7]. However, little information can be available on the phosphate removal properties of calcined paper sludge from aqueous solution.

In consideration of the effective utilization of resources, the aim of the study is the development of the recycling technology to prepare calcined paper sludge for recovery of phosphate from wastewater. We examined the effect of calcining condition on the phosphate removal properties of calcined paper sludge from aqueous solution.

\section{MAtERIALS AND MethodS}

\section{A. Materials}

In this study, the paper sludge, which was discharged from one of the domestic paper company in Japan, was used. After drying paper sludge in an electric oven, it was crushed and sieved in less than $250 \mu \mathrm{m}$ of particle size. The sludge was heated in the electric furnace at $800{ }^{\circ} \mathrm{C}$ for 0 - 60 minutes After the heating in electric oven, samples were cooled naturally to obtain the calcined paper sludge. The mass of the paper sludge after the calcining were measured, and examined mineral phases of calcined paper sludge by X-ray diffraction (XRD) (Rigaku, MiniFlex600).

\section{B. Removal Experiment}

The removal behavior of phosphorus ion from aqueous solution was examined as follows. Phosphoric solution of 10 $\mathrm{mmol} / \mathrm{L} \mathrm{KH}_{2} \mathrm{PO}_{4}$ was used. Calcined sludge $(1.0 \mathrm{~g})$ was added into a phosphorus solution $(200 \mathrm{~mL})$, and stirred at 600 $\mathrm{rpm}$ for 120 minutes at room temperature. During stirring, $\mathrm{pH}$ of the solution was measured with a $\mathrm{pH}$ meter (HORIBA, F-72), and a part of the solution $(1.5 \mathrm{~mL})$ was collected at varying times. The collected solution was filtered, and the phosphorus concentration in the filtrate was analyzed by the molybdenum blue method. The adsorption quantity of phosphate using calcined paper sludge at time $\mathrm{t}, q_{\mathrm{t}}$, and the removal percentage of phosphate from aqueous solution, $R_{\mathrm{t}}$, was calculated by difference of the phosphorus concentration of initial solution and that of the solution at time $t$, as follows.

$$
\begin{gathered}
q_{\mathrm{t}}=\left(C_{\mathrm{o}}-C_{\mathrm{t}}\right) / S \\
R_{\mathrm{t}}=\left(C_{\mathrm{o}}-C_{\mathrm{t}}\right) / C_{\mathrm{o}} \times 100
\end{gathered}
$$

$q_{\mathrm{t}}[\mathrm{mmol} / \mathrm{g}]$ : Quantity of adsorption at time $\mathrm{t}$ 
$C_{\mathrm{o}}[\mathrm{mmol} / \mathrm{L}]:$ Initial phosphorus concentration in the solution

$C_{\mathrm{t}}[\mathrm{mmol} / \mathrm{L}]:$ Measured phosphorus concentration in the solution at time $\mathrm{t}$

$S[\mathrm{~g} / \mathrm{L}]:$ The density of suspension

$R_{\mathrm{t}}$ [\%]: The removal percentage of phosphate from aqueous solution

After 120 minutes stirring, the solution was filtrated, and the residual substance was analyzed by XRD.

\section{RESUlTS AND DisCUSSION}

\section{A. Calcined Paper Sludge}

Fig. 1 shows the mass of the sample after calcining for various times. The mass of the samples decreased from $1 \mathrm{~g}$ to $0.6 \mathrm{~g}$ for 20 minutes, and then be almost constant.

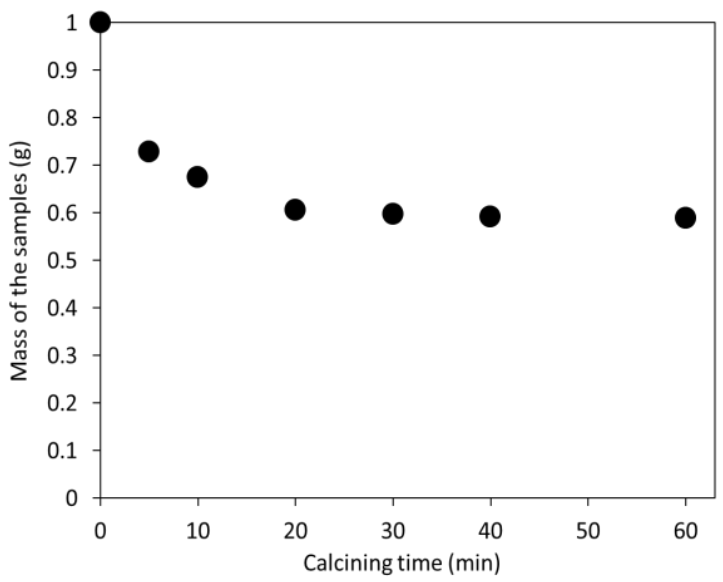

Fig. 1. The mass of the samples after calcining for various time.

Fig. 2 shows appearance of the calcined paper sludge. Before calcining, the color of the sludge was gray. At 5 minutes calcination, the sludge was tinged with white and whitened as a whole at more than ten minutes calcination.

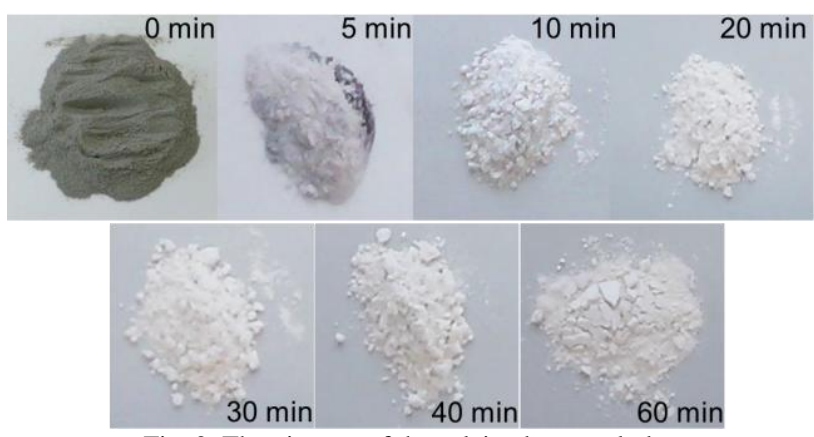

Fig. 2. The pictures of the calcined paper sludge.

The XRD pattern of the paper sludge and the calcined paper sludge are shown in Fig. 3. From XRD pattern of the paper sludge $(0 \mathrm{~min})$, the peaks of talc, calcite and kaolinite were confirmed. After 5 minutes calcination, the peaks of kaolinite in calcined paper sludge disappeared, and at more than 20 minutes calcination, the peaks of calcite drastically decreased. Talc was left after calcination. It was considered that calcite and kaolinite were reacted to form the amorphous material after 20 minutes calcination [8].

These results suggested that almost reaction in paper sludge by calcination occurs in 20 minutes, e.g. fiber included in paper sludge burnt and mineral phases, kaolinite and calcite, were reacted.

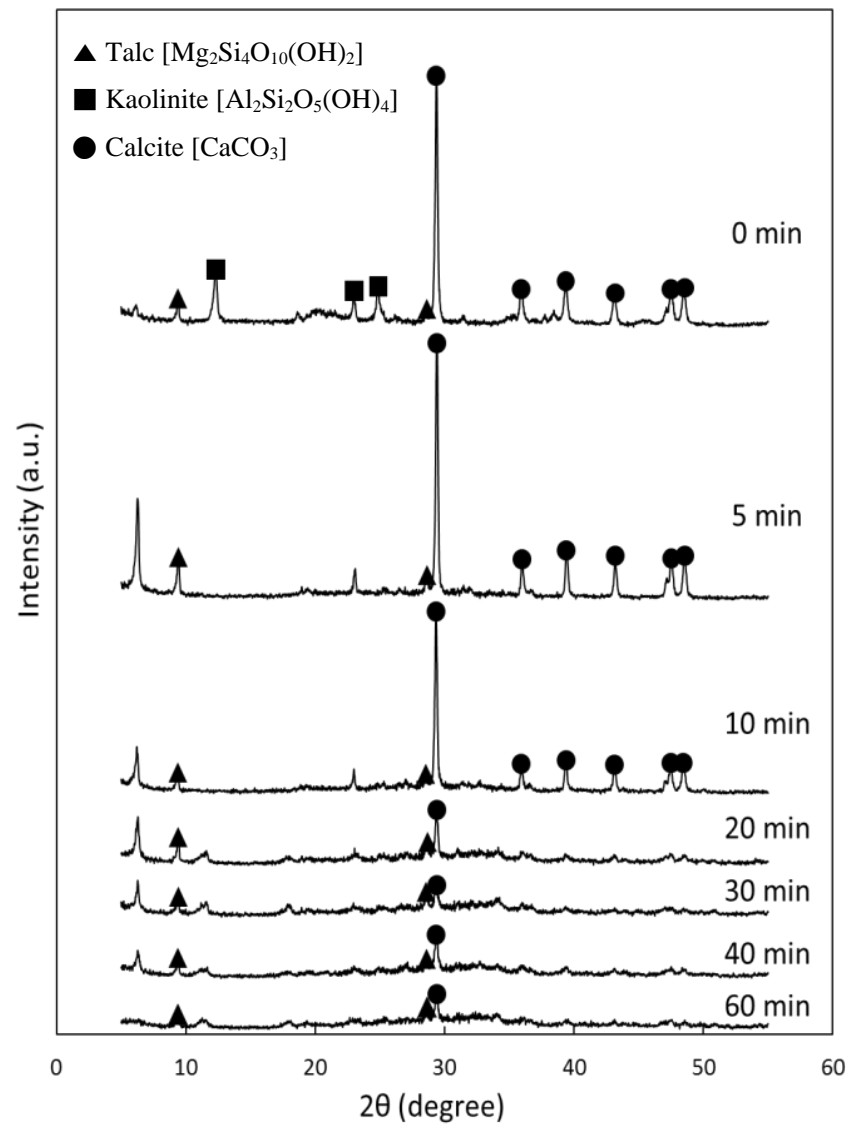

Fig. 3. XRD pattern of the calcined paper sludge.

\section{B. Phosphate Removal}

Fig. 4 shows $\mathrm{pH}$ of the solution as a function of reaction time during stirring experiment. Initial $\mathrm{pH}$ of the solution (before sample addition) was $4-4.5$, and after sample addition, $\mathrm{pH}$ of solutions rose. Thus, calcined paper sludge was alkaline substances [9]. The change of $\mathrm{pH}$ showed two tendencies. In the case of the paper sludge calcined for 0 - 10 minutes, $\mathrm{pH}$ rose to 6 . In the case of the paper sludge calcined for 20 - 60 minutes, $\mathrm{pH}$ to 6.5 .

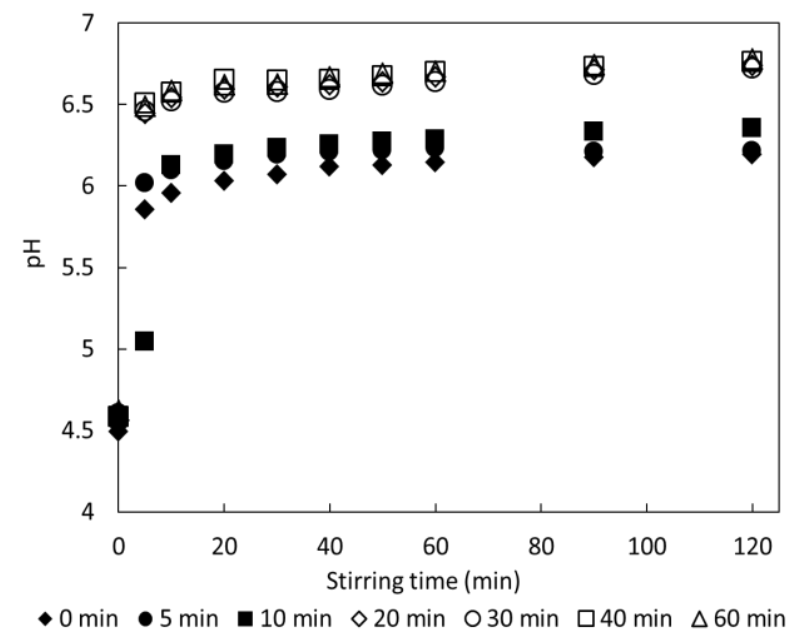

Fig. 4. pH of solutions during the reaction.

Fig. 5 shows the phosphorus concentration of solution as a function of reaction time during the experiment. When the 
sludge calcined for 0 - 10 minutes was added into a phosphoric solution, the phosphorus concentration of solution are almost same, while phosphorus concentration in solution decreased gradually using the sludge calcined for 20 -60 minutes.

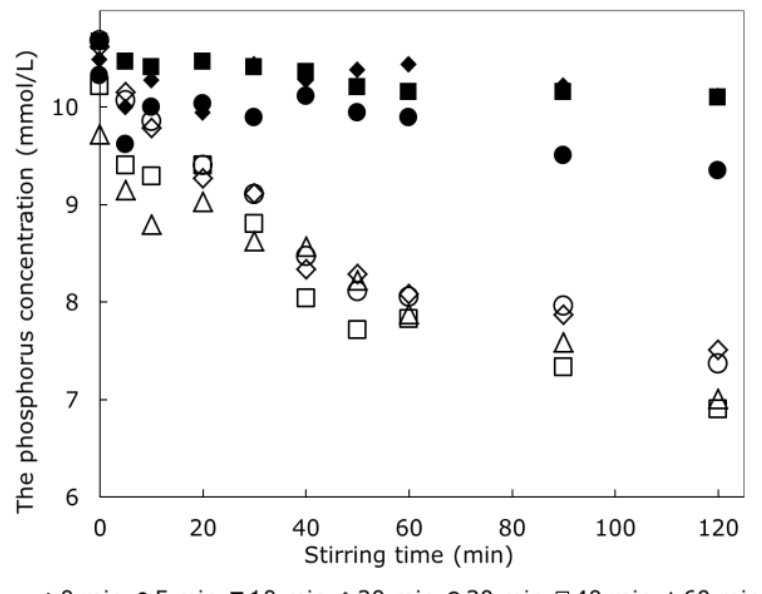

$\bullet 0 \mathrm{~min} \bullet 5 \mathrm{~min} \bullet 10 \mathrm{~min} \diamond 20 \mathrm{~min} 030 \mathrm{~min} \square 40 \mathrm{~min} \Delta 60 \mathrm{~min}$

Fig. 5. The phosphorus concentration of solution during reaction.

Fig. 6 shows a phosphorus removal after 120 minutes stirring by the sludge calcined at various time. In the case of 0 - 10 minutes, the removal rate was below $10 \%$. In the case of 20 - 60 minutes calcination, the removal percentages were relatively high $(25-30 \%)$.

The XRD patterns of the calcined paper sludge after the phosphorus removal experiment are shown in Fig. 7. The samples of 5 and 10 minutes showed the same patterns as those before the phosphorus removal experiment, which are shown in Fig. 2. In the samples calcined for more than 20 minutes, the peaks of the phosphate mineral, brushite, were confirmed.

From these results, it was considered that the amorphous phase, which was formed from kaolinite and calcite after 20 min calcination, in the calcined paper sludge and phosphorus in the solution were reacted to form brushite, to remove phosphate from phosphoric solution.

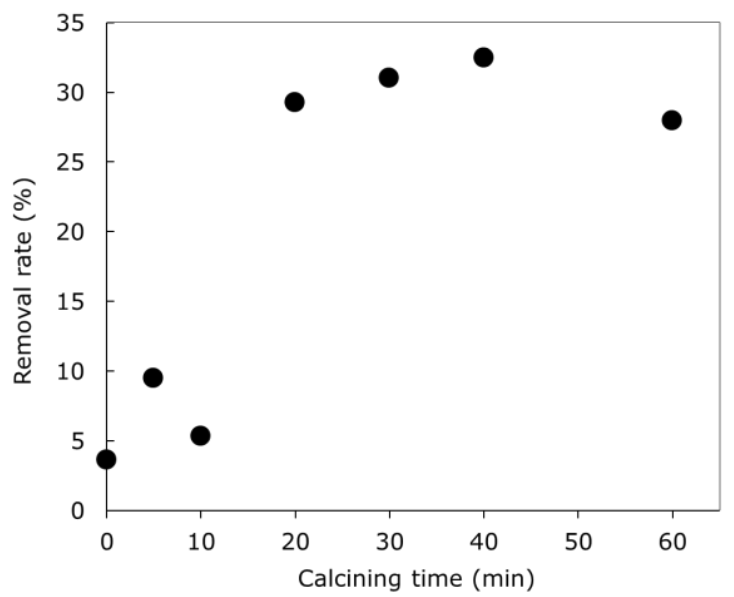

Fig. 6. A phosphorus removal by the sludge calcined at various time.

\section{Removal Kinetics}

Figure 8 shows the quantity of phosphorus adsorption using the sludge calcined for various time. The quantity of adsorption of the sample increased with increasing reaction time. In the case of $0-10$ minutes, the quantity of phosphorus adsorption was below $1 \mathrm{mmol} / \mathrm{g}$. while in the case of 20 - 60 minutes, the quantity of phosphorus adsorption reached approximately $4 \mathrm{mmol} / \mathrm{g}$.

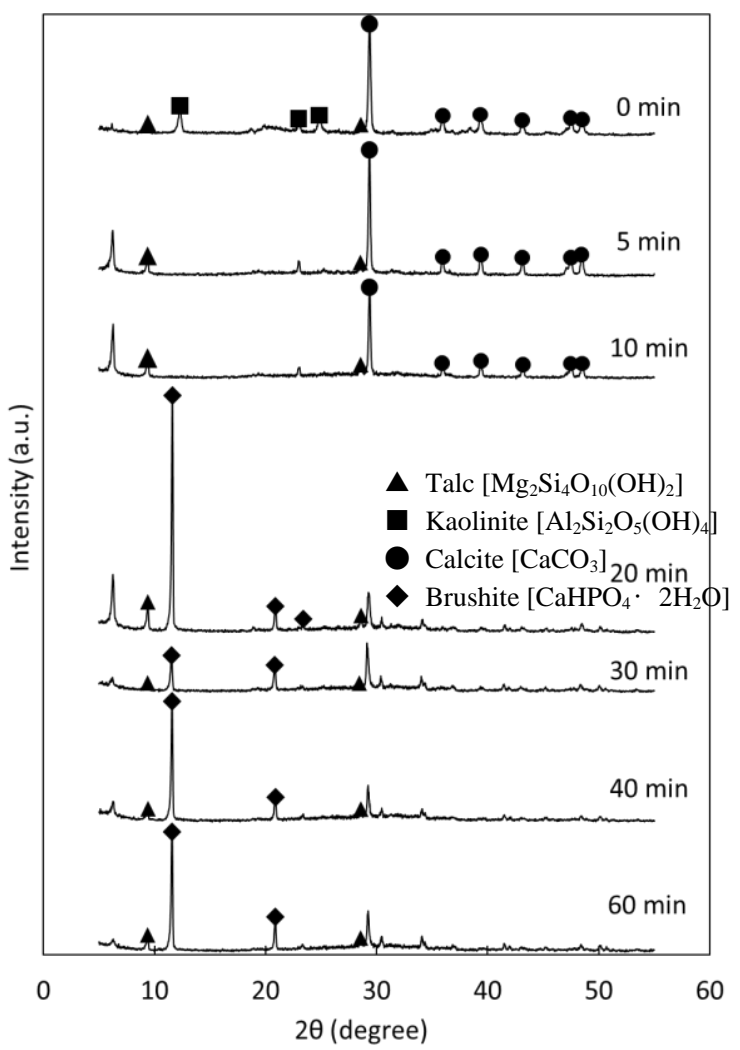

Fig. 7. XRD pattern of the calcined paper sludge after the phosphorus removal experiment.

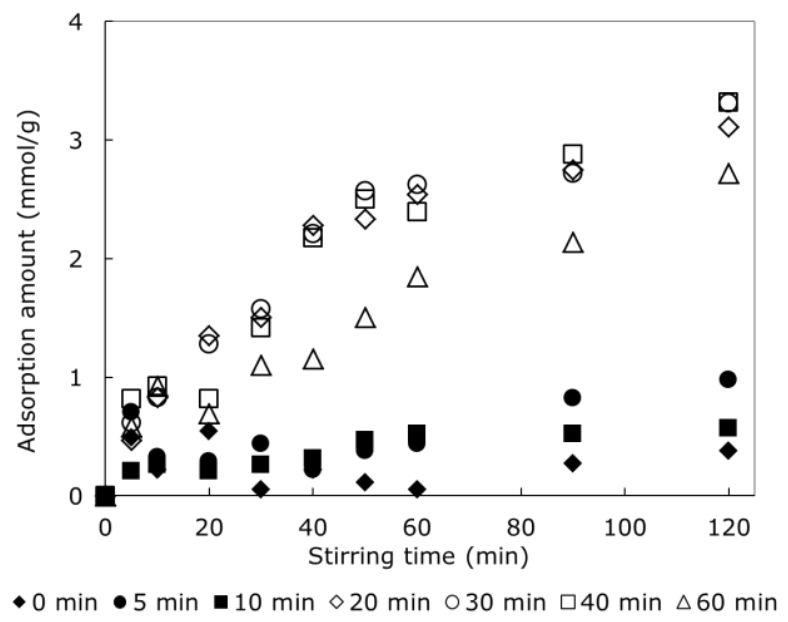

Fig. 8. The quantity of phosphorus adsorption.

From the results of phosphorus adsorption using the sample, adsorption kinetics was analyzed using the pseudo-first-order kinetic model [10] and pseudo-second-order model [11].

$$
\begin{gathered}
\ln \left(q_{e}-q_{t}\right)=\ln q_{e}-k_{1} \cdot t \\
t / q_{t}=1 /\left(k_{2} \cdot q_{e}^{2}\right)+1 /\left(q_{e} \cdot t\right)
\end{gathered}
$$

$q_{\mathrm{e}}[\mathrm{mmol} / \mathrm{g}]:$ The amount of phosphorus adsorbed at te $k_{1}$ [1/min]: The first order rate constant 
$k_{2}[\mathrm{~g} /(\mathrm{mmol} \cdot \mathrm{h})]:$ The second order rate constant

The experimental kinetic data were fitted using a pseudo-first-order kinetic model and a pseudo-second order kinetic model. The values of $k_{1}, k_{2}, R^{2}$ and $q_{\mathrm{e}}$ are set out in Table I. For the samples calcined for 0-10 minutes, little quantity of adsorption of phosphorus. Therefore, we discuss the results for the samples calcined for more than 20 minutes.
From the $R^{2}$ values, the experimental data fit much better to pseudo-first order model than to pseudo-second-order model, which denotes that the adsorption process is first-order. As a result of the calculation of $q_{\mathrm{e}}$, equilibrium adsorption quantity of phosphorus became $3.3-4.1 \mathrm{mmol} / \mathrm{g}$. It is noted that removal speed of samples, $k_{1}$, are almost same.

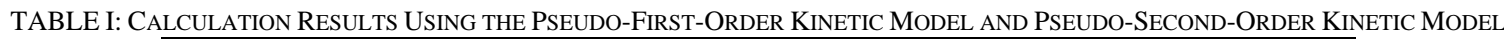

\begin{tabular}{ccccccc}
\hline \hline \multirow{2}{*}{ Time $(\mathrm{min})$} & \multicolumn{5}{c}{ Pseude-first-order } & \multicolumn{3}{c}{ Pseudo-second-order } \\
\cline { 2 - 7 } & $q_{\mathrm{e}}(\mathrm{mmol} / \mathrm{g})$ & $k_{1}(1 / \mathrm{min})$ & $R^{2}$ & $q_{\mathrm{e}}(\mathrm{mmol} / \mathrm{g})$ & $k_{2}(\mathrm{~g} /(\mathrm{mmol} \cdot \mathrm{min}))$ & $R^{2}$ \\
\hline 0 & 0.242 & 0.015 & 0.300 & 0.300 & 0.062 & 0.135 \\
5 & 0.927 & 0.014 & 0.613 & 1.079 & 56.98 & 0.361 \\
10 & 0.575 & 0.014 & 0.889 & 0.699 & 21.90 & 0.869 \\
20 & 3.586 & 0.011 & 0.936 & 4.132 & 168.4 & 0.979 \\
30 & 3.880 & 0.010 & 0.918 & 4.013 & 257.2 & 0.764 \\
40 & 4.135 & 0.010 & 0.949 & 4.587 & 236.2 & 0.790 \\
60 & 3.370 & 0.011 & 0.962 & 3.557 & 0.005 & 0.755 \\
\hline \hline
\end{tabular}

\section{CONCLUSION}

In this study, we examined the removal behavior of phosphate from aqueous solution using calcined paper sludge for the new utilization method of the paper sludge. The properties of paper sludge changes by heating at $800{ }^{\circ} \mathrm{C}$ for more than 20 min. Within 20 minutes, $40 \%$ weight loss occurs, the grey color changed to white, and mineral phase, kaolinite and calcite, formed amorphous phase.

The phosphate removal reaction occurred using the sludge calcined for more than 20 minutes, due to the formation of phosphate mineral, brushite. It is important for phosphate removal to create amorphous phase in the sludge. These phosphate removal reactions were accorded to pseudo-first-order kinetic model.

Conventional phosphorus removal method includes HAP (Hydroxy Apatite) method and MAP (Magnesium Ammonium Phosphate) method. These methods enable to recover the phosphorus by adding a reagent and crystallizing the phosphorus in the water treatment facilities. When these methods were used, the removal percentage of phosphorus extends to $80 \%$ [12]. We intend to manage our study technology by a similar process in the future. But, in the case of the calcined sludge (20 - 60 minutes calcination), the Phosphate removal percentages were $25-30 \%$. So, at this stage, the phosphorus removal with the sludge was lower than the existing models.

However, consider the cost and the utilization of resources, the phosphorus removal using the calcined sludge may be effective means. We will push forward the examination of the experiment condition to improve a phosphorus removal rate more in future.

\section{REFERENCES}

[1] T. Uchida, K. Katsushima, and Y. Suzuki, "Recycling of the wastepaper sludge," Rep. Hokkaido Ind. Res. Inst., vol. 298, pp. $125-132,2009$.
[2] N. J. Coleman, "Synthesis structure exchange properties of $11 \mathrm{~A}$ tobermorites from newsprint recycling residue," Mater. Res. Bull., vol. 40, pp. 2000-2013, 2005

[3] S. Fukugauchi and M. Morikawa, "Preparation of hydroxyapatite from paper sludge ash,” Pulp Pap. Ind., vol. 62, pp. 60-68, 2008.

[4] F. Ping, C. Chaopig, C. Diugsheng, and T. Zhixiong, "Carbonaceous adsorbents prepared from sewage sludge and its application for $\mathrm{Hg}$ adsorption in simulated flue gas," Chin. J. Chem. Eng., vol. 18, pp. 231-238, 2010.

[5] K. Shimamura, T. Kurosawa, and S. Watabe, "Phosphorus recovery using a crystallizer for sewage treatment," J. Ebara Corp., vol. 227, pp. $3-8,2010$.

[6] A. Kuroda, N. Takiguchi, and J. Kato, "Phosphorus utilization technology development corresponding to crisis prediction adsorbent developed from coal," J. Environ. Biotechnol., vol. 2, pp. 87-94, 2005

[7] T. Wajima and J. F. Rakovan, "Removal behavior of phosphate from aqueous solution by calcined paper sludge," Colloids Surf. A: Physicochem. Eng. Asp., vol. 435, pp. 132-138, 2013.

[8] T. Wajima and J. F. Rakovan, "Removal of fluoride ions using calcined paper sludge," J. Therm. Anal. Calorim, vol. 113, pp. 1027-1035, 2013

[9] T. Wajima, Y. Umeta, S. Narita, and K. Sugawara, "Adsorption behavior of fluoride ions using a titanium hydroxide-derived adsorbent," Desalin, vol. 249, pp. 323-330, 2009.

[10] Y. S. Ho, "Citation review of Lagergren kinetic rate equation on adsorption reactions," vol. 59, pp. 171-177, 2004.

[11] Y. S. Ho and G. McKey, "Pseudo-second order model for sorption processes," Process. Biochem., vol. 34, pp. 451-465, 1999.

[12] T. Tanaka and K. Shimamura, "Biological wastewater treatment process with chemical-phosphorus recover reactor," Journal of Environmental Biotechnology, vol. 4, no. 2, pp. 101-108, 2005.

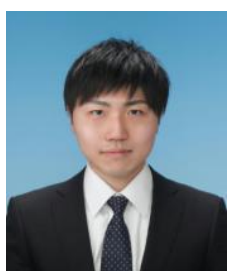

Kentaro Kimura was born in Shizuoka prefecture, Japan, in 1992. He received bachelor's degree in engineering from Chiba University, and graduated from Chiba University, Japan in 2015. He is studying on his master's course in the Department of Urban Environment Systems, Graduate school of engineering, Chiba University, Japan. 